\title{
Cifras Negras: uma análise da criminalidade oculta nos crimes de colarinho azul em Barreiras-Ba-Brasil e sua implicância nas estatísticas criminais das Agências de Controle Social Formal.
}

\begin{abstract}
Cifras negras: Un análisis del crimen oculto en los delitos de cuello azul en Barreiras-BA-Brasil y su implicación en las estadísticas penales de las agencias formales de control social.
\end{abstract}

Dark numbers: An analysis of the hidden crime in blue collar crimes in Barreiras-BA-Brazil and its implication in criminal statistics of Formal Social Control Agencies.

\author{
Sinara Cordeiro Moreira ${ }^{1}$ \\ Tauan Rodrigues Queiroz ${ }^{2}$ \\ Matheus dos Santos Alcântara ${ }^{3}$ \\ Aderlan Messias de Oliveira ${ }^{4}$
}

\begin{abstract}
RESUMO:
Este artigo tem como objetivo principal analisar a incidência das cifras negras no âmbito dos crimes de colarinho azul na cidade de Barreiras-BA-Brasil e sua implicância nas estatísticas criminais das agências de Controle Social Formal. Para isso, foi realizada uma pesquisa quanti-qualitativa, mediante aplicação de um formulário a 142 pessoas (cento e quarenta e duas). De $75,4 \%$ dos participantes da pesquisa, foi revelada a ocorrência de algum tipo de crime de rua, sendo, $66,4 \%$ relacionados a roubo. Também foi constatado que $46,2 \%$ não prestaram queixa alegando motivos diversos como: "a certeza da impunidade" ou até por "não acreditam no sistema". Em relação ao atendimento prestado pela polícia ao reportar os crimes, $50 \%$ alegaram que este foi ruim ou péssimo. Desse modo, fica evidente a relação entre a ineficiência do Controle Social Formal com o surgimento das cifras negras relacionadas aos crimes de colarinho azul na cidade de Barreiras-BA-Brasil.
\end{abstract}

Palavras-chave: Cifras negras. Controle Social Formal. Colarinho azul. Criminalidade oculta. Criminologia.

\footnotetext{
${ }^{1}$ Acadêmicos do 4o semestre do Curso de Direito, no Centro Universitário São Francisco de Barreiras (UNIFASB), Turma DI41M. E-mail: narinhacordeiro@gmail.com

${ }^{2}$ Acadêmicos do 40 semestre do Curso de Direito, no Centro Universitário São Francisco de Barreiras (UNIFASB), Turma DI41M. E-mail: tauan.rodrigues@hotmail.

${ }^{3}$ Acadêmicos do 4옹 semestre do Curso de Direito, no Centro Universitário São Francisco de Barreiras (UNIFASB), Turma DI41M. E-mail: com: theualcantara@gmail.com;

${ }_{4}^{4}$ Professor do colegiado de Direito do Centro Universitário São Francisco de Barreiras (UNIFASB), orientador, autor do projeto de pesquisa "Barreiras sob enfoque Criminológico". E-mail: aderlan@fasb.edu.br
}

Recibido: 10 de octubre de 2019. Aprobado: 5 de Diciembre de 2019. 


\title{
RESUME:
}

El objetivo principal de este artículo es analizar la incidencia de figuras negras en el contexto de delitos de cuello azul en la ciudad de Barreiras-BA-Brasil y su implicación en las estadísticas penales de las agencias formales de control social. Para ello, se realizó una investigación cuantitativa-cualitativa, mediante la aplicación de un formulario a 142 personas (ciento cuarenta y dos). Del $75.4 \%$ de los participantes de la encuesta, se reveló la ocurrencia de algún tipo de crimen callejero, con $66.4 \%$ relacionado con el robo. También se encontró que el $46.2 \%$ no presentó una queja alegando varias razones tales como: "la certeza de la impunidad" o incluso "no creen en el sistema". Con respecto a la asistencia prestada por la policía al denunciar los delitos, el $50 \%$ afirmó que era malo o muy malo. Por lo tanto, la relación entre la ineficiencia del Control Social Formal y la aparición de figuras negras relacionadas con crímenes de cuello azul en la ciudad de Barreiras-BA-Brasil es evidente.

Palabras Clave: Figuras negras Control social formal. Collar azul. Crimen oculto. Criminología.

\begin{abstract}
This article has as it's main objective to analyze the incidence of dark numbers, in the context of blue collar crimes in the city of Barreiras-BA-Brazil and it's implication in the criminal statistics of the Formal Social Control agencies. For this, a quantitative and qualitative research was performed, by applying a form to 142 people (one hundred and forty-two). Of the $75.4 \%$ of survey participants, it was revealed the occurrence of some type of "street crime", being $66.4 \%$ related to theft. It was also found that $46.2 \%$ did not complain about alleging various reasons such as: "the certainty of impunity" or even "do not believe in the system". Regarding the police service to report crimes, $50 \%$ claimed that it was bad or very bad. Thus, the relationship between the inefficiency of Formal Social Control or surgery of dark numbers related to blue collar crimes in the city of Barreiras-BA-Brazil is evident.
\end{abstract}

Keywords: Dark numbers. Formal Social Control. Blue collar. Hidden crime. Criminology.

\section{Introdução.}

Segundo Anuário Brasileiro de Segurança Pública 2019, no ano de 2018 foram mais de 1.475 .000 casos de roubo no país, sendo que na Bahia o número chega a pouco mais de 80.000 casos, equivalente a uma taxa de 545,7 casos por 100 mil habitantes de roubos registrados. Esses dados possuem um propósito significativo no que tange ter uma noção do patamar que a criminalidade alcançou no país.

Dessa forma, ao estudar e discutir sobre crimes e sua incidência na sociedade é concebível entender estas como conduta que visam um bem jurídico protegido por lei, ao passo que se compreende sua inerência à sociedade brasileira. Isto posto, o 
presente artigo visa discutir e trazer luz ao lado obscuro da criminalidade, conceituado como cifras negras no âmbito dos crimes de colarinho azul (crimes de rua).

O objetivo fundante se trata de compreender a incidência de tais crimes no Brasil, partindo do princípio de se estabelecer uma linha do tempo esboçando a criminalidade na sociedade e passando para uma conceituação teórica mais aprofundada quanto a historicidade das cifras negras. Outrossim, aprofunda-se no âmbito dos crimes de colarinho a fim de se compreender os crimes de colarinho azul (blue-collors). Nessa perspectiva analisa-se por fim, a implicância de tais crimes nas estatísticas das agências de Controle Social Formal.

\section{Declaração do problema.}

Por vezes, é perceptível a incidência de delitos que são cometidos e que não são reportados aos órgãos de Controle Social Formal, dando origem as cifras negras. Diante disso torna-se imprescindível questionar: quais fatores influenciam na tomada de decisão das vítimas em não reportar às instâncias penais, os delitos sofridos nas ruas?

A relevância da pesquisa far-se-á na necessidade de investigar não somente a incidência dos crimes de colarinho azul não reportados, mas também expor uma análise condensada da atuação das agências de Controle Social Formal no Brasil e seu papel como colaborador para a criação das cifras negras relacionadas a esse tipo de crime.

\section{Metodologia.}

O artigo em questão foi desenvolvido através de pesquisa quanti-qualitativa, por meio de um formulário aplicado online e pessoalmente a 142 respostas, com o intuito de se clarear esta criminalidade oculta presente na sociedade barreirense, ao descobrir pontos de ocorrência de crimes que não chegaram ao conhecimento do Poder Público e por quais razões isso ocorre. 
Entende-se como pesquisa quanti-qualitativa, aquela que além de utilizar-se de dados estatísticos para classificar as informações obtidas através de questionários ou formulários, também procura utilizar-se de estudos bibliográficos trabalhando com teorizações, conceituações, descrições, comparações e interpretações (OLIVEIRA, 2018).

\section{Fator histórico da criminalidade.}

A sociedade como se conhece surge em um momento de necessidade de união e sobrevivência que é demonstrado ao longo de toda a história. Deve-se destacar que os conflitos nascem de forma semelhante, pois partem da ideia da relação entre os seres humanos, dando a entender, portanto, sua inevitabilidade e inerência às relações humanas, não podendo ser encarado como algo totalmente negativo.

Nesse sentido, é possível determinar, com precisão, que atos de violência surgem da manifestação de um conflito latente. Dessa forma, é compreensível que interesses e valores sociais acabem por inevitavelmente se contrariar, levando ao surgimento de tais conflitos. Chega-se, então, a um entendimento que, para prevenir atos de violência (conflito manifesto) deva-se partir do princípio de compreender a subjetividade humana com o intuito de dirimir as divergências existentes.

Historicamente, o conflito mais antigo narrado encontra-se documentado na Bíblia Sagrada (Manuscritos do Mar Morto), no livro de Gênesis. Relata-se um conflito de interesses entre dois irmãos, Caim e Abel, que desencadeou o primeiro delito da história da humanidade: um homicídio.

Partindo desse pressuposto, é sabido que os conflitos se fortaleceram a partir da Revolução Agrícola, há cerca de dez mil anos, que foi o marco que levou à verticalização da sociedade - acumulação de riquezas e poderes, criação de reinados e escravização dos povos, o sedentarismo e o surgimento da propriedade privada. E assim, a violência começou a servir como o instrumento de poder, seja para perseguição ou para proteção desses bens (Vasconcelos, 2018).

Outrossim, nos estudos que intensificam o entendimento quanto a compreensão do surgimento da sociedade, bem como o caminhar que dela se estendeu para a existência da criminalidade, pode-se observar teorias importantes, tal qual a teoria do Contrato Social. Esta dispõe que a formação do Estado e da vida em sociedade surgem a partir de um "contrato social", que pode ser entendido como uma espécie 
de pacto ou acordo, que é firmado entre cada indivíduo e entre indivíduo e sociedade, naturalmente livre (Rousseau, 2001).

Foucault (2000) pondera que o homem vive na Era da Governamentabilidade desde o século XVIII, pois, através das contribuições dos teóricos Hobbes, Locke, e especialmente, Rousseau, com o desenvolvimento da obra "O Contrato Social", temse o marco da Economia Política. É com a constituição dessa ciência e segundo suas teorias que o ser humano passa a conviver em sociedade regrado por um modelo de controle ou organização social, que outrora era inexistente.

De tal forma, a liberdade humana dentro de uma sociedade passa a ser submetida a controles sociais formais (leis e regras institucionalizadas) que buscam garantir a proteção de cada indivíduo, bem como de seus direitos e deveres. Nesse sentido, há de se dizer que a criminalidade se predispõe em locais em que tais controles formais falham com seu objetivo fundamental de manter a ordem social.

Partindo de uma abordagem sociológica, Durkheim preleciona que o Fato Social representa a objetividade determinante da consciência coletiva sobre a consciência individual. Destarte, seriam características do Fato Social, em primeira instância, a coercitividade, ou seja, a pressão ou força social que os padrões sociais exercem sobre o indivíduo, obrigando e coagindo-o a reproduzi-los. Em segunda instância, a exterioridade: os padrões sociais representam uma realidade externa ao indivíduo, existindo originalmente fora da consciência individual. E em última instância, a generalidade, em que os padrões sociais são válidos para todos os indivíduos da sociedade, pois, existem em razão da coletividade e por isso são generalizantes (Durkheim, 1999).

Partindo dessa premissa, as sociedades mais complexas, onde vigora a solidariedade orgânica, são mais vulneráveis à Anomia Social que, do grego, at normas, representa comportamentos desviantes ocasionados pelo mau funcionamento ou ausência de normas (Durkheim, 1999). Ao passo do crescimento de anormalidades sociais, Durkheim entende que a solidariedade social é fundamental para que se mantenha a coesão e integração da sociedade.

Em contraponto a Lombroso e suas ideias atávicas de criminoso nato, Durkheim expõe que o crime é não patológico, não havendo herança biológica, mas sim o aprendizado do crime. Dessa forma, Shecaira (2012, p.173) aduz que "ninguém nasce 
criminoso, mas o delito (e a delinquência) é o resultado de socialização incorreta. Não há, pois, "herança biológica", mas sim um processo de aprendizagem que conduz o homem à prática dos atos socialmente reprováveis."

Mediante um paralelo, o raciocínio de Rousseau (2001), que estabelece a predisposição do homem a ser bom e a sociedade assim o corromper, da mesma forma, se faz presente conflitando com a teoria da "Tábula Rasa", de seu contemporâneo, Locke (1999) que em seu livro Ensaio Acerca do Entendimento Humano, inaugura o empirismo britânico, ao passo que buscou compreender a fonte do conhecimento humano. Locke (1999) afirma que cada indivíduo nasce como uma tábula rasa, uma folha em branco, a qual esta será escrita, ao passo que o indivíduo vive e adquire experiências de vida.

Assim, Rousseau, Locke e Durkheim, buscam propor teorias que acabam por preconizar a origem da criminalidade tendo em vista que se trata de um fator humano e inerente à sociedade. É notável que essa possui um papel mais que fundamental aqui a partir do momento que o sistema detém a capacidade de realçar os instintos criminosos de cada pessoa, bem como detém a competência para educar, prevenir, vigiar e punir.

Partindo do pressuposto com que é estabelecido toda a ideia de predispor o contexto da criminalidade na sociedade, entra-se em uma seara de discutir a questão de elucidar tais expoentes de criminalidade ${ }^{5}$, visando a busca pela paz. Essa, portanto, se faz através de meios que visem dirimir os conflitos existentes, é realçável, por conseguinte, o princípio da inafastabilidade da jurisdição previsto do art. 5ㅜ, XXXV, dispondo que "a lei não excluirá da apreciação do Poder Judiciário lesão ou ameaça a direito" (Brasil, 1988).

Dessa forma, entra-se em uma seara significativa no que tange os controles sociais formais, tratando-se da insurgência da criminalidade no país que não chega ao conhecimento do poder público, as chamadas cifras negras (zona obscura, dark number ou ciffre noir).

\footnotetext{
${ }^{5}$ Sendo a Criminologia uma ciência empírica, que parte da observação, indo na gênese do problema para estudálo, surge a necessidade de ser posto em consideração o aspecto biopsicosociológico da criminalidade. Dessa forma, o estudo do crime, do criminoso, da vítima e do controle social, leva em consideração a individualização de cada pressuposto do crime.
} 


\subsection{O fator histórico das cifras negras}

Esboçando uma linha histórica a respeito da criminalidade oculta, os estudos remontam à Escola Cartográfica, transição entre o classicismo e o positivismo, ou também denominada Estatística Moral. O precursor conceitual da alcunhada cifra negra foi o então belga Lambert Adolphe Jacques Quételet (1796-1874), que vendo o delito como um fenômeno inerente à sociedade e não patológico, observou a necessidade de o analisar quantitativamente. Sendo assim, utilizando-se do conhecimento empírico, o objetivo primeiro da tal Escola era observar a frequência média do delito, a sua distribuição e identificar suas variações. (Molina; Gomes, 2012).

Com o advento do lluminismo, nascendo a então chamada "Era das Luzes", ao findar do século XVIII e início do século XIX, decai toda a obscuridade que permeava o antigo Estado e surge a esperança da transparência.

Na verdade, qual é o sonho rousseauniano presente em tantos revolucionários? O de uma sociedade transparente, ao mesmo tempo visível e legível em cada uma de suas partes; que não haja mais nela zonas obscuras, zonas reguladas pelos privilégios do poder real [...] Um medo assombrou a segunda metade do século XVIII: o espaço escuro, o anteparo da escuridão que impede a total visibilidade das coisas, das pessoas, das verdades. Dissolver os fragmentos de noite que se opõem à luz, fazer com que não haja mais espaço escuro na sociedade [...] (Foucault, 2000, p. 215-216, grifo nosso)

É desse paradigma esperançoso, da busca por iluminação, que a estatística transita de primitiva, tornando-se uma estatística científica. Outrossim, diante das mudanças socioeconômicas, do crescimento demográfico do século XVIII, surgem os registros civis, tais como, censos populacionais, estudos demográficos e de registro, que foram se aperfeiçoando e incorreram na Estatística Criminal.

Noutro giro, já no século XX, Edwin Sutherland (1883-1950) é quem desenvolve a estatística oficial de cifra negra. Sutherland sofreu grande influência dos autores da Escola de Chicago, também denominados Teóricos Ecológicos ou da Desorganização 
Social. A escola de Chicago teve o condão de romper com a visão etiológica da delinquência, que surgira com o positivismo italiano de Lombroso (Shecaira, 2012).

Destarte, a ecologia criminal corroborou o uso dos métodos de pesquisa empírica na sociedade, contudo, os teóricos da Universidade de Chicago ignoravam a cifra negra, pois trabalhavam apenas com os dados oficiais, o que levava a uma defasagem da real quantificação delituosa (Shecaira, 2012).

Sutherland (2015) percebeu que as estatísticas não eram fiéis à realidade fática, identificando assim o instituto das cifras negras. Igualmente denominada criminalidade oculta ou zona obscura da criminalidade, consiste na diferença entre os delitos aparentes (criminalidade real) e os delitos latentes (criminalidade oculta), bem como os delitos que são efetivamente punidos pelo jus puniendi. Destarte, a cifra negra surge da lacuna existente nas estatísticas:

São eles, nessa ordem: a) crimes não observados embora praticados; b) crimes observados, mas não registrados; c) crimes registrados, mas não esclarecidos; d) crimes esclarecidos, mas não denunciados, e) crimes denunciados, mas que não resultam em condenação. (Veras, 2006, p. 86)

Diante disso, é possível verificar que a cifra oculta da criminalidade é uma fragilidade do sistema criminal decorrente da omissão, seja da vítima ou seja do próprio poder estatal. Por conseguinte, essa omissão se dá devido a diversos fatores que, segundo Penteado Filho (2012), ocorre, por parte da vítima: com a omissão do delito devido a vexame ou constrangimento (crimes contra a dignidade sexual); devido ao bem subtraído não ser assegurado e/ou possuir baixo valor econômico; pela (in) eficiência do aparato policial e judicial; decorrente do grau de parentesco da vítima com o agressor; ou até pelo não conhecimento dela a respeito da tipicidade penal do delito, dentre outros.

Ainda, na seara da vitimologia, há de se ressaltar de incorrer a omissão ainda por parte do próprio poder público. A taxatividade e etiquetamento (labelling approach) de quais delitos e quais criminosos, serão ou não, alvo da instalação de uma persecução penal é colocada, em especial, pelas instâncias de controle social formal (Becker, 2008). Há assim um processo de "filtração escalonado". (Cervini, 2010)

Admoesta Mandarino, et al. (2015, p. 289): 
Tanto os autores como as vítimas, as testemunhas, a polícia, especialmente os promotores de justiça e os tribunais, atuam como "filtros" determinantes na eleição de quais acontecimentos devem ser definidos como delitos e quais pessoas devem ser submetidas a um processo criminal, sofrendo as consequências deste estigma.

Não obstante, o papel da vítima no âmbito da criminalidade oculta, também pode-se analisar, de pronto, a responsabilidade cabível ao Estado, enquanto esse é único detentor do jus puniendi, ou seja, único órgão legitimado que possui o poder de punir. Sendo o titular da ação penal na seara de grande parte dos crimes, ele se faz inerte diante da criminalidade que lhe é revelada, colaborando para o surgimento da criminalidade oculta.

Se observarmos como opera o sistema penal nessas hipóteses conflitivas, veremos que na imensa maioria dos casos este não intervém (furtos, subornos, estupros, etc.) que somente em número ridiculamente ínfimo chegam à agência judicial, em outros intervém somente em alguns casos e contra determinadas pessoas [...] em outros tantos casos nunca intervém, apesar da grande frequência com que ocorrem [...] (Zaffaroni, 1999, p. 247, grifo nosso)

Ainda, é necessário ratificar que a pacificação sobre a criminalidade oculta está longe de ser alcançada. Ficou claro de que diversos são os fatores que contribuem para a existência das zonas obscuras da criminalidade na sociedade.

\section{Os crimes de colarinho.}

Sendo o crime um fato inerente a relação humana em sociedade, sua prática se torna rotineira e se torna o objeto de estudo para a criminologia. Com os avanços dessa ciência, surgem estudos sobre os tipos de colarinhos da criminalidade, sendo o mais famoso e propulsor desse tipo de conceituação, o crime de colarinho branco, conhecido como White Collor Crime.

Abordando esse tema, Sutherland (2015) expõe que existem determinados crimes que não são punidos, visto que, apesar de serem positivados na seara penal, os 
praticantes de tais delitos gozam de certos favorecimentos econômicos e sociais. Tal posicionamento, na pirâmide social, faz enfraquecer o poder punitivo do jus puniendi estatal, sendo esses praticantes, tratados, em regra, de forma diferenciada do restante da sociedade, pois:

pessoas da classe econômica mais alta são mais poderosas politicamente e financeiramente e escapam da prisão e da condenação em maior escala que as pessoas que carecem deste poder. Pessoas abastadas podem contratar advogados habilidosos e outras vezes podem influenciar a administração da justiça em seu favor de maneira mais efetiva que pessoas da classe socioeconômica mais baixa (Sutherland, 2015, p. 32).

Ao procurar distinguir esses crimes praticados pela elite social da esfera penal geral, Sutherland (2015) conceitua-os como crimes de colarinho branco, fazendo menção aos trajes usados pelos executivos e políticos que, em regra, são os praticantes de tais delitos. Esses delitos têm relação intrínseca com a função econômica desemprenhada pelos agentes, tendo relação com crimes ligados à violação de confiança e corrupção.

Outra colaboração importante do autor foi a crítica ao estudo atávico lombrosiano e o determinismo social de Durkheim, pois para ele, o crime não possui relação com aspectos biológicos e nem econômicos, e sim com as relações sociais e interpessoais em que o indivíduo está associado, podendo acontecer na classe baixa e alta, comungando com o adágio popular: "a ocasião faz o ladrão".

Desse pensamento, nasce a teoria da Associação Diferencial, ao explicar que o crime advém de um processo de aprendizagem, ensejado pelo ambiente de convívio e pelo momento no qual o indivíduo está inserido. Sutherland desenvolveu essa construção teórica pautado nos ideais de seu preletor Gabriel Tarde (1843-1904), que aduzia que a delinquência é uma profissão, e como tal, necessita também ser aprendida. Com isso, a Associação Diferencial procura explicar que o crime acontece em todas as searas da sociedade (Shecaira, 2012).

Em contraste aos crimes de colarinho branco, surgem das classes econômicas mais vulneráveis outra pigmentação para o colarinho do crime, agora de coloração azul, dando origem aos crimes de colarinho azul. Tais crimes são praticados, nas ruas de 
todo o Brasil e é o foco da fúria do poder punitivo estatal, onde o direito penal atua com todo vigor.

\subsection{Colarinho azul, a seletividade do direito penal no espectro da criminologia crítica.}

Cotidianamente se faz presente na sociedade a prática de certas condutas delitivas, sendo estas praticadas em ambientes públicos e de vigilância espontânea do Estado. Esses crimes são praticados por uma parcela específica da sociedade, como os assaltos ou furtos que acontecem nas ruas, sendo tais condutas definidas como crimes de colarinho azul ou crimes de rua.

Os crimes de colarinho azul (blue collor crime) adquirem esse nome devido as vestimentas dos operários dos Estados Unidos no século XX, pois era característica desses trabalhadores a uniformização utilizando as cores azuis no âmbito das suas funções desempenhadas nas grandes fábricas (Biffe Junior; Leitão Junior, 2017).

Os crimes de colarinho azul, em grande parte, possuem uma menor engenhosidade do que as condutas ilícitas cometidas pelos grandes empresários e políticos. Os agentes que praticam essas condutas, em muitos casos, atuam de forma amadora, praticando os denominados "crimes de rua", que são cometidos em ambientes públicos supervisionados pelo Estado, como o crime tipificado no artigo 155 do Código Penal, o furto (Marçal; Masson, 2017).

Os agentes transgressores dessas normas penais, em regra, são pessoas que possuem poder aquisitivo baixo e não estão presentes nas elites sociais. Como essas pessoas não gozam de status social elevado, a atuação do Estado se torna mais rígida e punitiva, pois como consequência do mundo capitalista ao qual vivenciamos, a falta do capital torna o indivíduo mais vulnerável aos excessos ocasionados pelo poder punitivo estatal e a seletividade do Direito Penal.

Ao partir da Criminologia Crítica, podemos observar que a criminalidade é um status atribuído a determinados indivíduos, sendo esse concebido por dois critérios: o primeiro critério trata-se de uma seleção de bens jurídicos a serem tutelados pelo Direito Penal; e o segundo, é a seleção de determinados indivíduos estigmatizados que realizam as infrações presentes na norma penal (Baratta, 2002). 
Como elo mais fraco de representatividade é o poderio financeiro, as populações de classes econômicas mais baixas, na maior parte dos casos, recebem o direcionamento da norma penal e de suas sanções. Isso traz um desequilíbrio na balança da justiça, sendo os crimes de colarinho azul, punidos de forma violenta, e os crimes de colarinho branco, em regra, passando despercebidos aos olhos do Estado.

Outro fator relevante para a estigmatização de criminalidade da classe econômica mais baixa em detrimento da classe econômica mais alta é a indústria midiática. Esta influencia a população sobre o que é certo e errado, de forma sensacionalista, tornando os crimes praticados pela população da classe econômica mais baixa, muito mais reprováveis dos que os crimes praticados pelos ricos, visto que, muitas dessas agências são propriedades de empresários que podem estar envolvidos nesses tipos criminais de colarinho branco (França, 2014).

Ao ratificar essa ideia de estigma do pobre e impunidade dos crimes praticados pelos ricos, o Ministro do Supremo Tribunal Federal, Luiz Fux (2013), ao julgar o caso do Mensalão (Ação Penal n. 470), se pronunciou da seguinte forma ao proferir o seu voto:

O desafio na seara dos crimes do colarinho branco é alcançar a plena efetividade da tutela penal dos bens jurídicos não individuais. Tendo em conta que se trata de delitos cometidos sem violência, incruentos, não atraem para si a mesma repulsa social dos crimes do colarinho azul.

Para Fux, a reprovação social para os crimes de colarinho azul são muito maiores do que para os crimes de colarinho branco, sendo que o próprio Direito Penal, ao escolher os bens jurídicos mais importantes para serem protegidos, resolveu ser mais seletivo e punitivo para com os agentes infratores de crimes praticados pela população subalterna, e, não só isso, a repulsa social formada também direciona seu caráter punitivo para os menos favorecidos economicamente.

Essa seletividade do Direito Penal atraiu a atenção de estudiosos da criminologia crítica marxista, em que as elites sociais, por serem detentoras de grande poderia econômico, acabam determinando quais os bens jurídicos que serão protegidos, e também as suas respectivas sanções. Sendo assim: 
O direito penal tende a privilegiar os interesses das classes dominantes, e a imunizar do processo de criminalização comportamentos socialmente danosos típicos dos indivíduos a elas pertencentes, e ligados funcionalmente a existência da acumulação capitalista, e tende a dirigir o processo de criminalização, principalmente, para formas de desvio típicas das classes subalternas. (Baratta, 2002, p.165)

À luz da Criminologia Crítica, percebe-se uma área de discriminação feita pela seletividade operativa do sistema penal, que, nas palavras de Zaffaroni (1999, p. 246), "A escolha, como sabemos, é feita em função da pessoa, o bom candidato, é escolhido a partir de um estereótipo [...]". Sendo assim, há uma visível afronta ao Estado Democrático de Direito, quando uma pessoa é punida pelo seu perfil, estilo de vida, ou seja, punida pelo que ela é, utilizando-se do direito penal do autor, e não punida pelo que ela fidedignamente fez, violando o direito penal do fato.

Logo, é possível averiguar a predisposição do Direito Penal em imputar sua norma sancionadora para os crimes de colarinho azul, dando uma ideia de justiça por aplicar a norma, mas, em contrapartida, uma ideia nítida de injustiça, que é a sua aplicação heterogênea, pois os crimes de colarinho branco, em muitas vezes, passam despercebidos do olhar punitivo do Estado.

\section{Análise dos resultados da pesquisa de campo acerca da criminalidade oculta nos crimes de colarinho azul em Barreiras-Ba-Brasil e sua implicância nas estatísticas criminais das agências de controle social formal.}

Mediante estabelecido anteriormente, foi realizada a pesquisa com o objetivo de analisar a incidência das cifras negras nos crimes de colarinho azul e a implicância nas estatísticas criminais das agências de controle social formal no extremo Oeste da Bahia, na Cidade de Barreiras, tendo ela, de acordo com o IBGE (2017), 137.427 habitantes.

Nesse sentido, foram aplicados formulários, online e físico, compostos por 12 perguntas, sendo 10 objetivas e 02 subjetivas, tocantes à criminalidade oculta, aos crimes de rua sofridos e não reportados ao poder público, ao atendimento recebido 
pelos órgãos competentes, e à motivação que levou os inquiridos a não reportarem os delitos.

Sendo assim, quando questionados sobre terem sofrido a ocorrência de algum tipo de crime de rua (a saber: roubo, furto ou dano), $75,4 \%$ dos participantes responderam "sim", já terem sofridos a ocorrência de tais delitos.

Gráfico 01: Você já sofreu a ocorrência de algum crime de rua?

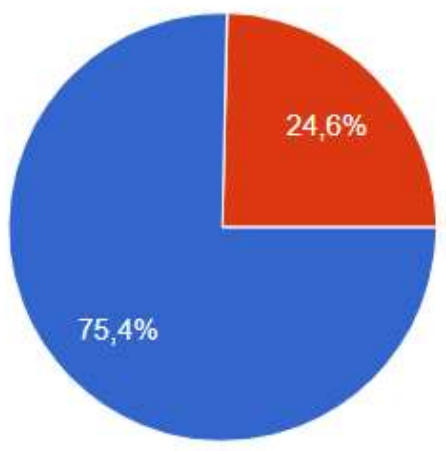

Fonte: Pesquisa de Campo (2019)

Os delitos chamam-se informalmente "de rua" por ocorrerem nas ruas (colarinho azul) local onde o controle social formal, na forma de polícias ostensivas, que têm o dever legal de prevenir e reprimir o crime, deveria se fazer presente, e fora inerte ou ausente. Ademais, é possível aqui verificar a ineficiência da aparelhagem política do Estado no que toca à repressão e prevenção dos delitos nas ruas barreirenses, e proteção da população transeunte.

Gráfico 02: Caso a resposta anterior seja "sim", indique a quantidade:

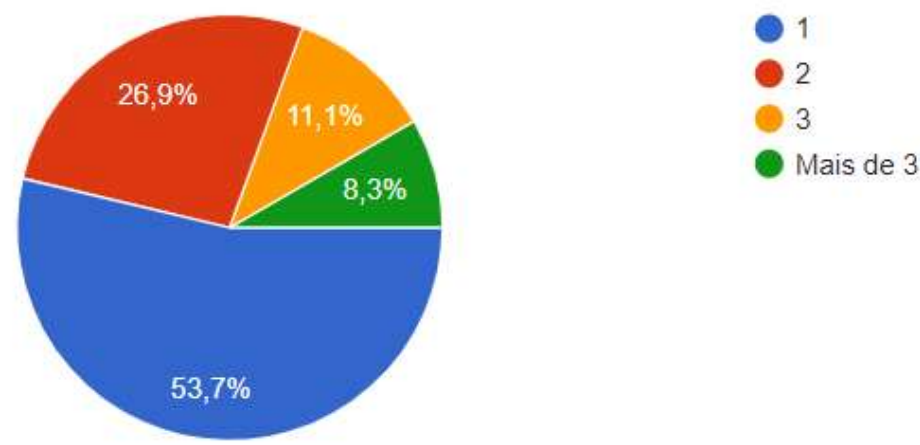

Fonte: Pesquisa de Campo (2019) 
Nota-se aqui que $26,9 \%$ dos participantes sofreram duplamente a ocorrência de tais crimes nas ruas e $8,3 \%$ padeceram com mais de 03 delitos, o que apenas reforça o entendimento da ineficácia do controle social formal em face de tais ocorrências.

Gráfico 03: Selecione o(s) crime(s) sofridos:

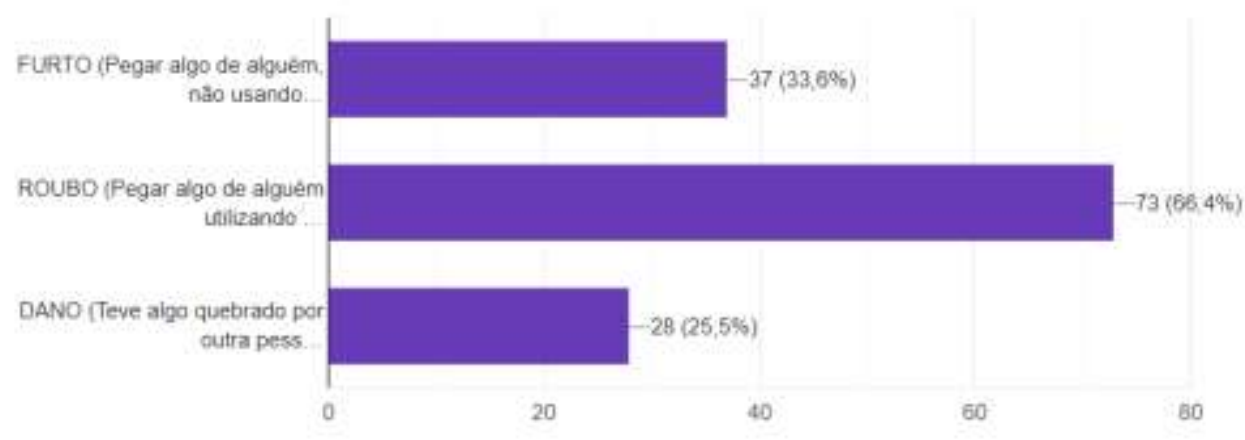

Fonte: Pesquisa de Campo (2019)

Ao analisar os dados tabulados, verifica-se a maior incidência de $66,4 \%$ sobre o delito de roubo, crime mais complexo e prejudicial, tanto para a vítima quanto para o agente. Nesse sentido, a legislação penal vigente é silente no que tange à ação penal em tais delitos, sendo assim, é entendimento pacífico na doutrina, de que será proposta ação penal pública incondicionada. Portanto, o Ministério Público, enquanto aparelho do controle social formal e dominus littis da ação penal pública, tem o dever legal de iniciá-la.

Isso quer dizer que o Ministério Público não necessita de autorização ou manifestação da vontade de quem quer que seja para iniciá-lo. Basta constatar a prática de crime. Bem como a autoridade policial, ao ter conhecimento de crime de ação penal pública incondicionada, deverá de ofício, instaurar inquérito policial. (Bittencourt, 2018, p.942)

Em que pese ao roubo, ainda se constata a ocorrência de $36,6 \%$ de crimes de furto e $25,5 \%$ de crimes de dano, que não obstante, seguem igualmente o mesmo regramento da ação penal pública incondicionada legítima do Parquet. 
Gráfico 04: Você procurou as autoridades após sofrer o crime?

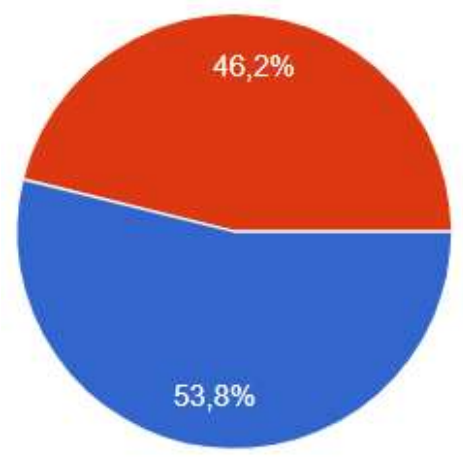

Fonte: Pesquisa de Campo (2019)

Percebe-se graficamente que é muito tênue a linha entre os participantes que procuraram as autoridades policiais após suportarem o crime e os que não procuraram: 53,8\% responderam que "sim" e 46,2\% responderam que "não". Dessa verifica-se que metade dos participantes foram vítimas de crimes e não os reportaram aos órgãos do controle social formal, fazendo incidir as cifras negras da criminalidade.

Por conseguinte, na questão posterior Descreva os motivos que te levaram a não denunciar, foram variadas as justificativas, a saber: "não resolução do caso, pouca importância dada pelas autoridades"; "não esperança de ter o bem restituído, burocracia do poder público"; "o que foi tomado de mim era de pouco valor"; "os policiais não ajuda agente e não dá atenção (sic)"; "na primeira vez procurei e nada se resolveu, e na segunda nada"; "foi denunciado, mas nada fazem"; "certeza da impunidade"; "medo, preguiça e descrença"; "baixo valor"; "morosidade"; "Ineficácia na recuperação do bem roubado, na maioria dos casos semelhantes"; "Impossibilidade de efetividade da justiça"; "Falta de credibilidade dos órgãos competentes."; "Foi roubo de celular acabei não denunciando pois não vão fazer nada mesmo... Só perca de tempo (sic)"; "não acredito no sistema".

Não obstante as respostas serem subjetivas, submetidas à esfera social e circunstâncias subjetivas inerentes de cada indivíduo, tais como grau de instrução, gênero, capacidade socioeconômica e idade, é perceptível a unificação e pacificação dos motivos que levam as vítimas a não denunciarem o sofrimento dos crimes: a ineficácia do controle social formal perante a sociedade. 
Gráfico 05: Se você procurou a polícia, como foi o atendimento?

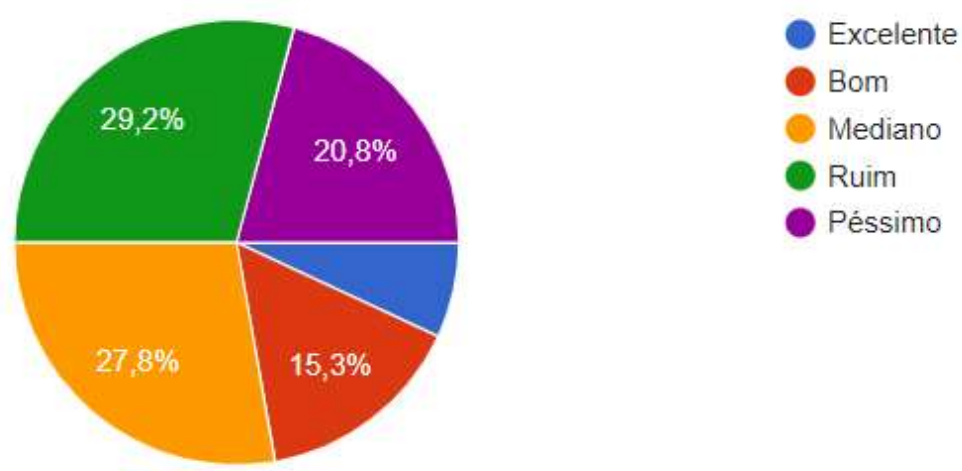

Fonte: Pesquisa de Campo (2019)

Mediante o supracitado, $29,2 \%$ dos participantes afirmaram ter sido ruim o atendimento oferecido pelas autoridades policiais, 20,8\% afirmaram ter sido péssimo, contra apenas 6,9\% afirmado ser excelente. Essa estatística apenas ratifica o fato de que o controle social formal não tem sido bem visto perante a sociedade e o mau atendimento tem corroborado essa visão.

Gráfico 06: Com a denúncia, você teve seu bem restituído ou o dano reparado?

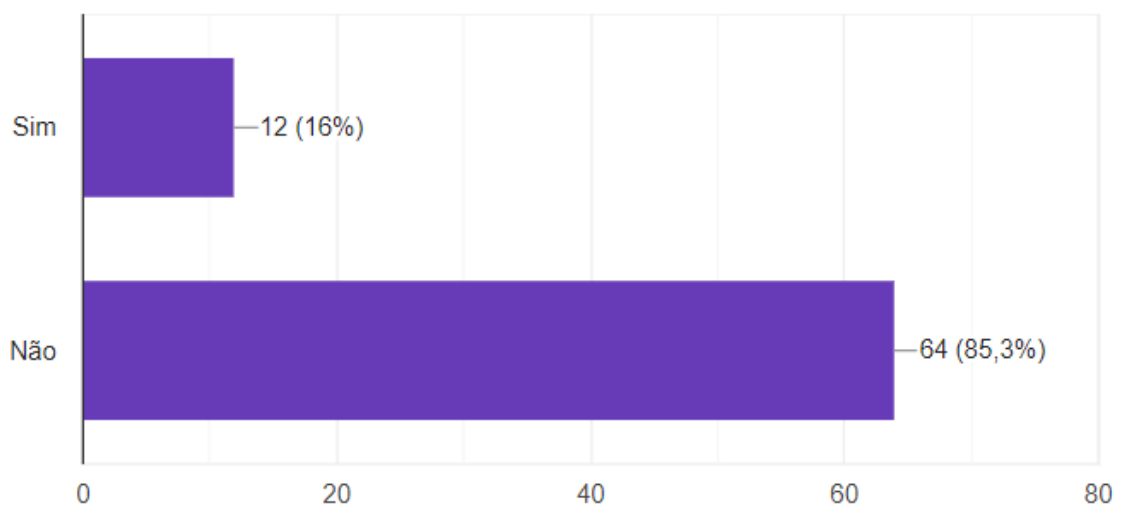

Fonte: Pesquisa de Campo (2019) 
Gráfico 07: Se não teve o bem restituído ou o dano reparado após a denúncia, sabe dizer o por quê?

O roubo de celular, a maioria das vezes nāo
recupera
Falta de condições de trabalho para setor
de investigação!!
Não chegou nem ao menos a ser
investigado
Sem relevância para o estado
As autoridades não tem o interesse de
ajudar e quando tem nāo tem o auxilio
necessário.
Não investigaram.
Das 3 ocorrências de furto, apenas 1 bem
(motocicleta) foi restituido 6 anos após a
ocorrência, os demais casos ficaram sem
solução.

O roubo de celular, a maioria das vezes nāo
recupera

Falta de condições de trabalho para setor de investigaçāo!!

Nāo chegou nem ao menos a ser

Sem relevância para o estado

As autoridades não tem o interesse de ajudar e quando tem nāo tem o auxilio necessário.

Não investigaram.

Das 3 ocorrências de furto, apenas 1 bem (motocicleta) foi restituído 6 anos após a solução.

Fonte: Pesquisa de Campo (2019)

\section{Porque a policia não deu muita importância ao caso.}

nāo sei informar

Porque a policia não tem a intenção de restituir ou reparar o dano de ninguém.

Não faço nem ideia.

Porque nesse pais nada funciona como deveria.

Porque uma vez que perde é dificil reparar, a polícia no Brasil é incompetente.

Nāo, mas queria saber.

A não restituição do bem e não reparação do dano são também fatores essenciais para não prestação da queixa referente aos delitos, $85,3 \%$ dos participantes informaram não ter tido tais benefícios com a queixa-crime. Diante das respostas, verifica-se reiteradamente a mesma linha de raciocínio da maioria absoluta dos participantes a respeito do aparelho de controle social formal.

\section{Considerações Finais.}

Foi possível verificar a incidência de cifras ocultas da criminalidade desde tempos remotos. Os dados colhidos decorrentes da pesquisa de campo sobre o instituto das cifras negras, no âmbito dos crimes de colarinho azul e seu impacto nas estatísticas das agências de controle social formal, permitiram não somente constatar a presença instigante da criminalidade oculta na sociedade barreirense, como também possibilitaram observar os motivos pelos quais esses crimes não chegam ao conhecimento estatal. 
De tal forma, foi possível também observar a descrença por parte da população ao aparelho de segurança do Estado, que em suma a enxerga como incompetente e ineficaz, sendo, em muitas das justificativas preenchidas nos formulários, os motivos principais pela não denunciação dos crimes de colarinho azul ocorridos.

Em relação aos crimes de rua ocorridos no Brasil, houve uma forte presença no que tange aos índices de crime de roubo (art. 157, CP), sendo esse o mais citado pela população que participou da pesquisa, seguidos de furto e dano, presentes no Código Penal respectivamente nos artigos 155 e 163.

Ao passar para a questão da atuação policial no combate dessas infrações penais, em prol de estabelecer segurança pública de qualidade, foi notável o patamar atingido de descrédito direcionado a estes, haja vista que o atendimento nas delegacias, para aqueles que buscam reportar o crime ocorrido, não foi nem de perto satisfatório na visão da maioria dos entrevistados.

O presente artigo vislumbrou, acima de tudo, colocar em pauta um assunto descomunal e oculto aos olhos da maior parte da população, contribuindo de tal forma com sua discussão mais aforada no meio acadêmico. Diante disso, foi alcançado o objetivo fundante da análise dos fatores primordiais na tomada de decisão de cada indivíduo ao não reportar a ocorrência de crimes e não exercer um direito fundamental seu no que tange à segurança pública de qualidade. 


\section{Referências.}

BARATTA, Alessandro; tradução Juarez Cirino dos Santos. (2002). Criminologia crítica e crítica do direito penal: Introdução à Sociologia do Direito Penal. 3. ed. Rio de Janeiro: Editora Revan.

BECKER, Howard. (2008). Outsiders: estudos de sociologia do desvio. Rio de Janeiro: Jorge Zahar.

BIFFE Junior, João; Leitão Junior, Joaquim. (2017). Concursos públicos terminologias e teorias inusitadas. São Paulo: Editora Forense Itda.

BITENCOURT, Cezar Roberto. (2018). Tratado de direito penal: Parte geral (arts. 1ํㅡㄴ a 120). 24. ed. São Paulo: Saravia Jur, v. 1.

BRASIL. [Constituição (1988)]. Constituição da República Federativa do Brasil de 1988. Brasília, DF: Presidência da República, 2019. Disponível em: http://www.planalto.gov.br/ccivil_03/constituicao/constituicao.htm. Acesso em: 17 nov. 2019.

PRESIDENTE DA REPÚBLICA. Decreto-Lei 2.848, de 07 de dezembro de 1940. Código Penal. Diário Oficial da União, Rio de Janeiro, 31 dez. 1940. Disponível em: http://www.planalto.gov.br/ccivil_03/decreto-lei/del2848.htm. Acesso em: 18 nov. 2019.

Supremo Tribunal Federal. Ação Penal 470. Ministro Luiz Fux. Brasília, 22 abr. 2013. Disponível em: ftp://ftp.stf.jus.br/ap470/InteiroTeor_AP470.pdf/

CERVINI, Raúl. A cifra negra da criminalidade oculta. Revista Doutrinas Essenciais de Direito Penal, v. 1.

DURKHEIM, Émile.(2002). As regras do método sociológico. São Paulo: Martin Claret.

EDUARDO, Brandão. (1999). Da divisão do trabalho social / Émile Durkheim; tradução Eduardo Brandão. - 2a ed. - São Paulo: Martins Fontes, 1999. - (Coleção tópicos) Título original: De la division du travail social. 
FÓRUM Brasileiro de Segurança Pública. (2019) Anuário Brasileiro de Segurança Pública. Disponível em: http://www.forumseguranca.org.br/wpcontent/uploads/2019/10/Anuario-2019-FINAL_21.10.19.pdf. Acesso em: 18 nov. 2019.

FOUCAULT, Michel. (2006). Microfísica do poder. Organização e tradução de Roberto Machado. Rio de Janeiro: Graal.

FRANÇA, Leandro Ayres. (2005). A criminalidade de colarinho-branco: a proposição teórica de Edwin Hardin Sutherland: subtítulo do artigo. Revista de Direito Econômico e Socioambiental: subtítulo da revista, CURITIBA, v. 5, n. 21, p. 53-74. Disponível em: https://periodicos.pucpr.br/index.php/direitoeconomico/article/viewFile/14690/14192. Acesso em: 28 out. 2019.

GÊNESIS. In: Bíblia Sagrada. (1990). Trad. Ivo Storniolo Euclides Martins Balancin. Edição Pastoral. São Paulo: Paulus. IBGE. População. Disponível em: https://cidades.ibge.gov.br/brasil/ba/barreiras/panorama. Acesso em: 02/01/2020.

LOCKE, John. (1999). Ensaio acerca do Entendimento Humano. Editora Nova Cultural Ltda., São Paulo.

MANDARINO, Renan Posella et al. (2015). A participação da vítima no controle da cifra oculta da criminalidade. Doutrina Nacional, [s. I.], v. 37.1, p. 281-299. Disponível em: Revista do Programa de Pós-Graduação em Direito da UFC. Acesso em: 28 out. 2019.

MARÇAL, Vinícius; Masson, Cleber. (2017). Crime organizado. São Paulo: Método.

MOLINA, Antônio Garcia-Pablos de; Gomes, Luiz Flávio. (2012). Direito Penal fundamentos e limites do Direito Penal. 3 ed. São Paulo: Editora Revista dos Tribunais.

OLIVEIRA, Aderlan Messias de. (2018). Manual de tcc aplicado ao curso de direito: guia prático na produção de projeto de pesquisa, artigo científico, monografia, formatação e defesa oral. Rio de Janeiro: Gramma.

PENTEADO Filho, Nestor Sampaio. (2012). Manual esquemático de criminologia- 2. ed. - São Paulo: Saraiva. 
ROUSSEAU, Jean Jacques. (2001). O Contrato Social. [S. I.: s. n.].

SHECAIRA, Sérgio Salomão. (2012). Criminologia. 4. ed. rev. e atual. São Paulo: Editora Revista dos Tribunais.

SUTHERLAND, Edwin H. (2015). CRIME DE COLARINHO BRANCO: VERSÃO SEM CORTES. Edição. Rio de Janeiro: REVAN.

VASCONCELOS, Carlos Eduardo de. (2018). Mediação de conflitos e práticas restaurativas. 6. ed. - Rio de Janeiro: Forense; São Paulo: MÉTODO.

VERAS, Ryanna Pala. (2006). Os crimes do colarinho branco na perspectiva da sociologia criminal. Orientador: Doutor Oswaldo Henrique Duek Marques. Dissertação de Mestrado (Direito) - PUC São Paulo, [S. I.], 2006. Disponível em: www.dominiopublico.gov.br. Acesso em: 28 out. 2019.

WEFFORT, Francisco C. (2011). Os clássicos da política. 14. ed. São Paulo: Ática. V ZAFFARONI, E. R. (1991). Em busca das penas perdidas. A perda da legitimidade do sistema penal. Rio de Janeiro: Revan. 